\title{
Prognostic value of the electroretinogram in severe recent ocular trauma
}

\author{
G. E. JAYLE AND A. F. TASSY \\ From the Clinique Ophtalmologique, Faculté de Médecine de Marseille
}

In patients suffering from severe recent ocular trauma it is important to know the extent of the retinal damage before assessing the possible recovery of visual function. Ophthalmoscopic examination of the fundus is often impossible because of opacities of the ocular media caused by the trauma. In such cases the electroretinogram (ERG) is of value in assessing the state of the retina, but very few electrophysiological investigations have so far been published on such cases. This is probably because there are various technical difficulties in recording the ERG in these patients. An attempt has been made in our laboratory to overcome these difficulties.

The present paper analyses the ERGs recorded in 6I eyes in which severe and recent (less than 2 months) trauma had rendered the fundus invisible. In nineteen eyes the first record of the ERG was made during the first 5 days after the trauma, and in the rest between the sixth and the sixtieth day. This was because most of the patients had first been treated in other hospitals and later referred to our laboratory.

These 6 I eyes had sustained perforating wounds, intraocular foreign bodies, or severe contusions (Table); all foreign bodies were extracted during the first 20 days after the injury.

Table Analysis of 6 1 cases, 32 of which were followed long enough for the final visual acuity to be assessed

\begin{tabular}{|c|c|c|c|c|c|c|c|c|c|c|c|c|c|c|c|c|c|c|c|c|c|}
\hline \multirow{2}{*}{\multicolumn{2}{|c|}{$\begin{array}{l}\text { Group ERG } \\
\text { No. of cases }\end{array}$}} & \multicolumn{5}{|c|}{$\begin{array}{l}\text { Extinguished } \\
\text { Ex }\end{array}$} & \multicolumn{5}{|c|}{$\begin{array}{l}\text { II } \\
\text { Diminished }\end{array}$} & \multicolumn{5}{|c|}{$\begin{array}{l}\text { III } \\
\text { Subnormal }\end{array}$} & \multicolumn{5}{|c|}{$\begin{array}{l}\text { IV } \\
\text { Normal }\end{array}$} \\
\hline & & \multirow{2}{*}{\multicolumn{2}{|c|}{$\begin{array}{ll}* & \dagger \\
T & F \\
6 & 2\end{array}$}} & \multicolumn{3}{|c|}{${ }_{A}{ }_{B}$ isual acuity } & \multirow{2}{*}{$\begin{array}{l}* \\
\\
8\end{array}$} & \multirow{2}{*}{$\begin{array}{l}+ \\
F \\
6\end{array}$} & \multicolumn{3}{|c|}{${ }_{A}^{V i s u a l}$ acuity } & \multirow{2}{*}{$\begin{array}{l}* \\
10\end{array}$} & \multirow{2}{*}{$\begin{array}{l}+ \\
F \\
4\end{array}$} & \multicolumn{3}{|c|}{${ }_{A}^{\text {Visual acuity }}$} & \multirow{2}{*}{$\begin{array}{l}* \\
T \\
4\end{array}$} & \multirow{2}{*}{$\begin{array}{r}+ \\
F \\
2\end{array}$} & \multicolumn{3}{|c|}{$\underset{A}{\text { Visual acuit }}$} \\
\hline Trauma & $\begin{array}{l}\text { Perforating } \\
\text { wounds }\end{array}$ & & & 2 & o & o & & & 5 & $\mathbf{I}$ & o & & & I & I & 2 & & & o & o & 2 \\
\hline & $\begin{array}{l}\text { Foreign } \\
\text { bodies }\end{array}$ & 2 & 2 & 2 & o & $\mathbf{o}$ & 2 & o & $\mathbf{o}$ & o & o & 2 & 0 & o & o & $\mathbf{o}$ & 5 & 4 & o & I & 3 \\
\hline & Contusions & 7 & 3 & 3 & 0 & $\mathbf{o}$ & 3 & I & o & I & o & 6 & 4 & 0 & o & 4 & 6 & 4 & o & o & 4 \\
\hline & Total & 15 & 7 & 7 & 0 & o & 13 & 7 & 5 & 2 & o & 18 & 8 & I & I & 6 & 15 & 10 & o & I & 9 \\
\hline
\end{tabular}

\section{Method}

Three types of recording technique were used according to the technical difficulties encountered in these injured eyes.

(I) In many contusions and in most cicatrized perforating wounds it was possible to use a contact lens electrode and the standard technique of our laboratory. This method (Jayle's adapto-dynamic technique) has been described more extensively elsewhere (Jayle, Boyer, and Camo, 1959; Jayle, Boyer, and Saracco, 1965 ; Jayle, Tassy, and Graveline, 1968). 
The pupils are dilated. The patient is first light-adapted for 3 minutes (the adapting light is white and provides an illumination of approximately 3,00o lux at the level of the corneae). The patient is then dark-adapted for 12 minutes; during that period, responses to white, red, and blue flashes given successively at 30 -second intervals are recorded. The stimulator is a Retinéclat (Alvar Electronic); we use flashes of arbitrary intensity 4 on this apparatus. These flashes are white, short (approximately $50 \mu \mathrm{sec}$.), and intense. The quantity of illumination measured at corneal level is approximately 5 lux.sec. and as the flashes are $50 \mu \mathrm{sec}$. in duration, the peak illumination on the corneae is above 100,000 lux. Red and blue flashes are obtained by using Kodak Wratten filters 26 and $47 \mathrm{~B}$.

Since 1964 we have added to our standard method a study of the oscillatory potential of the ERG during dark and light adaptation (Jayle and others, I968; Tassy, I966). The oscillatory potential is recorded in response to flashes twenty times brighter than those used in Jayle's adapto-dynamic technique. This stronger intensity was added in our laboratory to the commercially available stimulator and designated intensity 5. The ERGs are averaged by an electronic averager (CAT 40oB, Mnemotron).

(2) In very severe contusions and recently-sutured perforating wounds it was impossible to use a contact lens electrode, and we therefore tested three possible substitutes:

(a) Small silver electrodes stuck on the skin a few millimetres from the margin of the lids. Using an averager we showed (Tassy, 1966; Tassy, Jayle, and Graveline, 1968) that these electrodes permitted not only the a- and b-waves but also the oscillatory potential to be studied.

(b) Cotton-wick electrodes located on the conjunctiva.

(c) Hook-shaped eyelid retractors (Fig. I); these electrodes were found to be the most practical for routine work in wounded eyes. We tested several kinds of hook electrodes; the simplest hook (bottom of Fig. I) is very light ( $0.2 \mathrm{~g}$.) and therefore better for wounded eyes. This hook can easily be made from $0.7 \mathrm{~mm}$. diameter silver wire, the tip being rounded by melting it in the flame of a Bunsen burner. The hook remains quite malleable and can be bent with the fingers so as to be

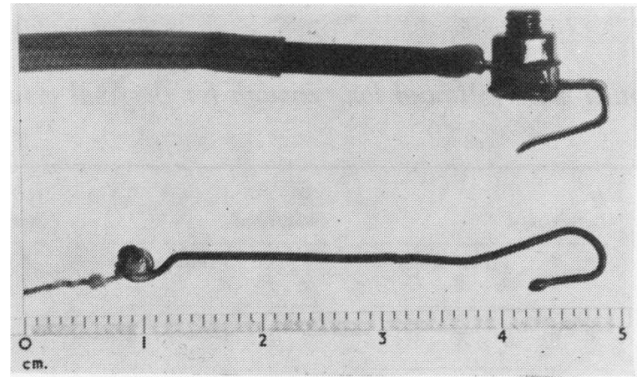

FIG. I Hook-shaped eysid retractor electrodes. The ukper hook electrode is adapted from Jacobson, Uchida, and Masuda (1966). The lower hook was designed in our laboratory. Scale in centimetres

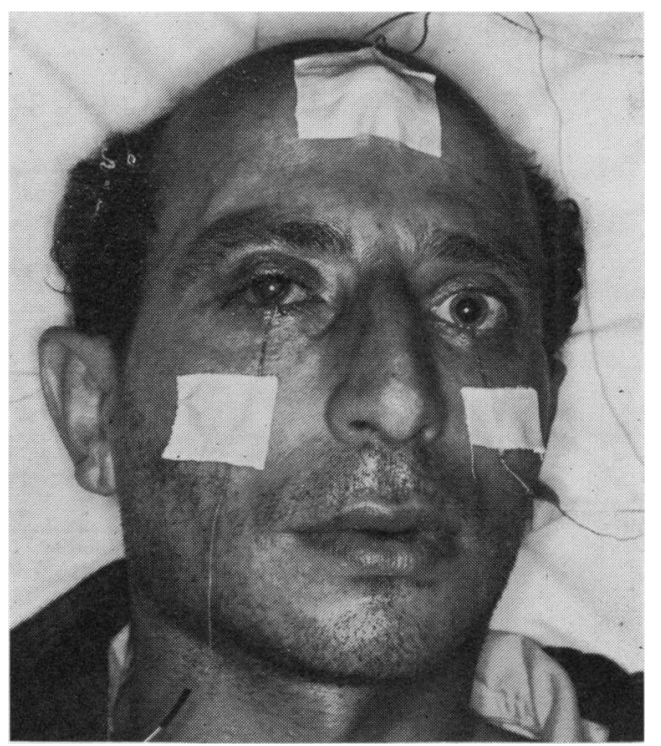

FIG. 2 The simplest kind of hook electrodes (lower hook in Fig. I) attached to a patient with a perforating wound of the right eye caused by a magnetic foreign body located in the vitreous. The eye showed a lacerated cataract with incorporation of lens matter in the corneal wound. The wound was sutured and the foreign body removed by the posterior route immediately after the trauma. The ERG was recorded 5 days after the trauma, while the patient was lying in bed 
fitted and secured on the lid even if it is injured and oedematous. The whole hook, except the tip, is insulated with a thin coat of nail varnish. The wire soldered to the hook electrode is glued to the cheek with adhesive plaster (Fig. 2). The hook remains in close contact with the corneal limbus, and thus enables the whole electroretinographic course of dark adaptation, as described above, to be recorded.

The responses recorded with the hook have an almost identical waveform to those obtained with contact lens electrodes (Fig. 3), and their amplitude is about 50 to 70 per cent. of that provided by the latter. The background noise is sometimes more marked with hook electrodes but does not prevent the interpretation of the records. A record with very little noise may be obtained using the averager (Fig. 3).

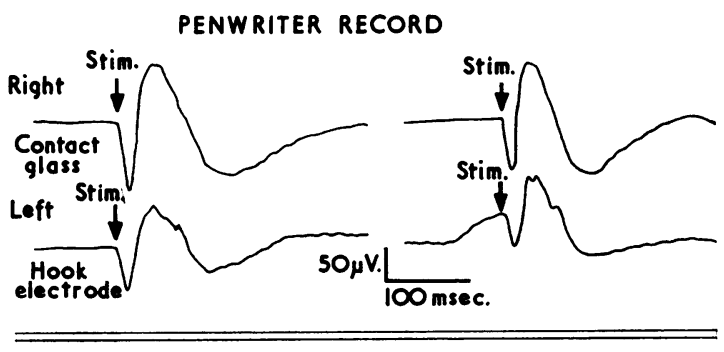

AVERAGE

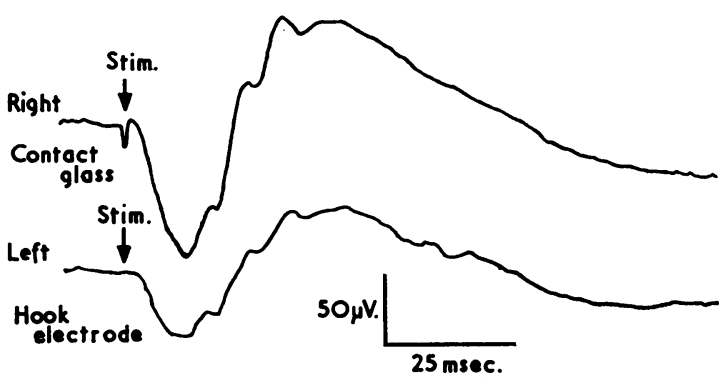

FIG. 3 (ERG No. 4478). Comparison of ERGs recorded in a normal subject with a contact lens electrode on the right eye and a hook electrode on the left. White flashes of intensity 4

Upper traces: penwriter records (time constant $0.3 \mathrm{sec}$.)

Lower traces: averages of twenty responses (time constant $0.5 \mathrm{sec}$.)

(3) Some patients who had not yet undergone surgery for a perforating wound or intraocular foreign body could not be moved, but the procedure could be carried out while the patient lay on a bed or stretcher. Hook or skin electrodes were used and the responses to a few white, red, and blue stimuli were recorded using flashes of intensity 4. An averaged record was made of the response to white flashes first of intensity 4 and then of intensity 5 .

It was thus possible to record without risk the ERG of most traumatized eyes the day of the accident or very soon afterwards.

\section{Results}

As we used several different recording techniques we could not compare the recorded responses directly. The ERGs were therefore classified in four groups according to their amplitude measured as a percentage of the normal with each technique. This classification was made using only the responses to white flashes (the reasons for this choice will be given below in the Comments section).

In the standard Jayle's adapto-dynamic technique the normal range of amplitude was known from previous studies (Jayle and others, I959, I965); with the other techniques, the amplitude of the undamaged eye was taken as normal (none of these eyes were diseased). 
GROUP I EXTINGUISHED (or nearly extinguished) ERGS

Reduced to less than ro per cent. of the normal amplitude.

GROUP II GREATLY DIMINISHED ERGS

Between Io and 50 per cent. of the normal.

GROUP III SUBNORMAL ERGS

Between 50 and 75 per cent. of the normal.

GROUP IV NORMAL ERGS

Above 75 per cent. of the normal.

The ERG was recorded less than 2 months after the trauma in 61 eyes, but only 32 of these were followed up long enough to know the final state of the visual acuity. For $\frac{O}{0}$. instance, among patients with traumatic cataracts, we considered that the final recovery was known only if the cataract had been extracted.

These 32 eyes were then classified into three groups according to the recovery of the visual acuity (see Table).

GROUP A

Visual acuity less than $0 \cdot 05$ or atrophic and painful eyes which had to be enucleated.

GROUP B

Visual acuity between $0 \cdot 05$ and $0 \cdot 3$.

GROUP C

Visual acuity greater than $0 \cdot 3$.

The prognostic value of the ERG recorded soon after the trauma was assessed by comparing the ERG classification with the visual acuity classification.

GROUP I EXTINGUISHED

Of the fifteen eyes in this group, seven were followed long enough to know the evolution of the visual acuity. All seven were placed in Group A; three had to be eviscerated or enucleated and the others had only perception of light.

Case I (No. 2370)

A man aged 46 years was admitted to hospital after receiving a blow with the fist on the left eye; apparently he had only a hyphaema, but he was deaf, dumb, and illiterate so that it was impossible to 0 know whether he saw the light or not. The ERG was extinguished. 2 months later, the hyphaema was absorbed and an extensive vitreous haemorrhage was observed. 5 months after the accident the eye became atrophic and painful and had to be eviscerated (Group IA).

GROUP II GREATLY DIMINISHED

Of the thirteen eyes in this group seven were followed long enough to know the final visual function. Five did not recover any useful vision or had to be eviscerated (Group A), and the other two were classified in Group B, the final visual acuity being 0.2 and $0.3 \div$ respectively. An example of an eye in Group II A is given below.

Case 2 (No. 3652 )

A man aged 43 years had his right eye pierced by a small lead shot which lodged in the ethmoid. He was admitted to a neighbouring hospital, where a severe vitreous haemorrhage was observed, and 
was sent to our laboratory for an ERG recording 7 days after the accident. The ERG was found to be greatly reduced (Fig. 4). I4 days after the trauma the eye appeared to be "quiet" although the fundus could not yet be seen because of a vitreous haemorrhage. Before being discharged the patient was again sent to our laboratory. The penwriter record (Fig. 4) indicated that the ERG was extinguished, but there was an ample negative wave due to a blink movement in response to each flash and this wave might conceal a small or late ERG. In fact the averaged record showed a small abnormal ERG. Because of these ERG findings a retinal detachment was suspected and the patient was kept in hospital. A week later the vitreous became clearer and examination with the Goldmann three-mirror contact lens revealed a definite retinal detachment. A sclerectomy was performed and the retina reattached. A year after the accident the retina remained attached but the ERG was extinguished and the visual acuity reduced to perception of light (Group II A).

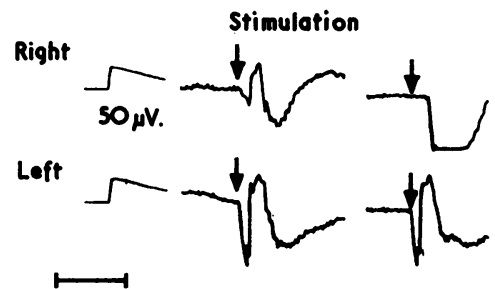

250 msec. I (7th doy) II (14th doy)

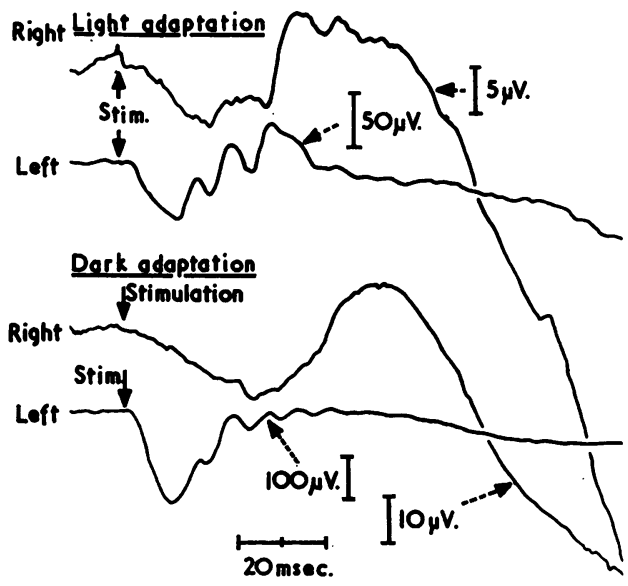

FIG. 4 Case 2 (ERG No. 3652). Right eye pierced by a small lead shot; left eye normal

Upper: penwriter record made with Jayle's adapto-dynamic technique 7 and 14 days after the accident. Figure shows only the responses to a white flash after I I min. dark adaptation; time constant $0 \cdot 3 \mathrm{sec}$.

Lower: averaged record made 14 days after the accident; average of thirty responses to white flashes of intensity 5 after 13 min. dark adaptation; stimulation frequency $1 / 6$ hertz; time constant $0.5 \mathrm{sec}$.

Note difference in scale between the records of the two eyes.

GROUP III SUBNORMAL

Of the eighteen eyes with subnormal ERGs during the first 2 months after trauma, eight were followed long enough to know the final visual function. One had a bad result (Group A) due to traumatic uveitis and another had a visual acuity of 0.2 (Group B) after the discission of a traumatic cataract. The other six patients regained a visual acuity greater than 0.3 (Group C); an example of these is given below.

Case 3 (No. 2745)

A girl aged 15 years had received a blow with a shoe on her left eye. There was a complete hyphaema and later an extensive vitreous haemorrhage was seen. The ERG was subnormal (Fig. 5 , overleaf). 
For 8 months there was partial blood-staining of the cornea and no fundus reflex because of vitreous opacities, the visual acuity being reduced to perception of light. The ocular media began to clear and a year after the accident the patient had recovered a visual acuity of 0.9 ; the fundus then became visible and was found to be normal (Group III G).

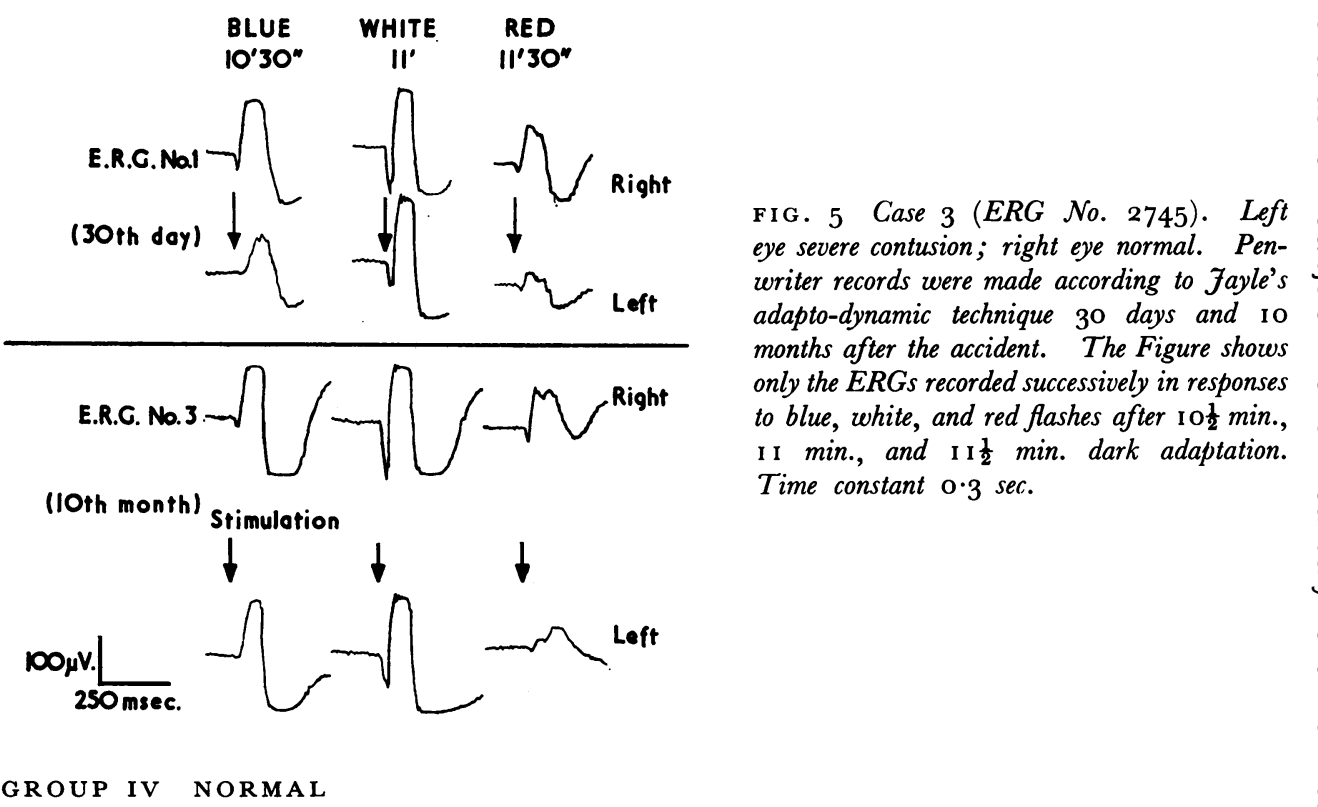

Of fifteen eyes with normal ERGs, ten were followed long enough to know the final visual function. Nine of the ten had a good result (Group C). One eye (see case note No. 2404) $\stackrel{\varrho}{\vec{F}}$ recovered only a visual acuity of $0 \cdot 3$ (Group B) because of a late retinal detachment which a repeated ERG helped to diagnose.

Case 4 (No. 2404)

A man aged 59 had a magnetic foreign body in the vitreous, which was removed by the posterior route. A traumatic cataract was developing, and the first ERG recorded 17 days after the accident was within normal limits (Fig. 6), but one week later the ERG was found to be greatly diminished, and it was suspected that a retinal detachment was probably concealed by the opaque lens. After

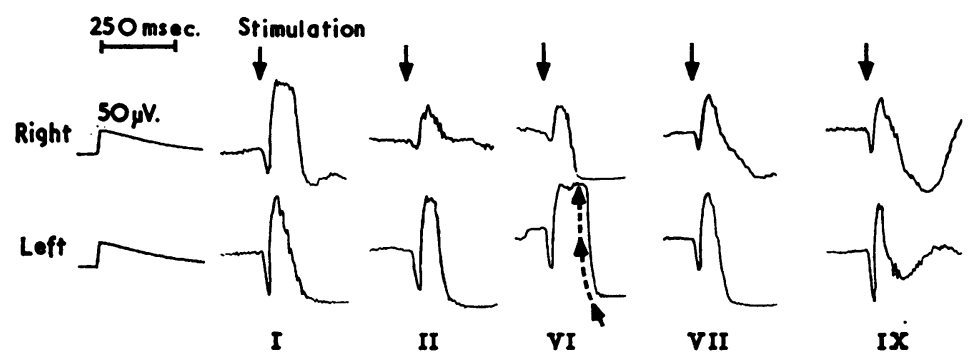

(17th day) (25th day) (6th month) (9th month) (20th month)

FIG. 6 Case 4 (ERG No. 2404). Right eye magnetic foreign body removed; left eye normal. Nine records $\stackrel{\circ}{\vec{D}}$ were made between the $\mathrm{I} 7$ th day and the 20th month after the accident. Figure shows only the responses to a white $\stackrel{\bigcirc}{\square}$ flash after I I min. dark adaptation (penwriter record: Jayle's adapto-dynamic technique). The sixth record is $\mathbb{\mathbb { Q }}$ distorted by a sudden upward deflection (arrows) caused by lid movement 
full mydriasis it was possible to see a localized peripheral retinal detachment, and this and the cataract were treated surgically; 20 months after the accident the retina was still reattached and the visual acuity was 0.3 (Group IV B).

\section{Comments}

Eyes with an extinguished or nearly extinguished ERG (Group I) did not recover any useful vision. Therefore, when for clinical reasons a sympathetic ophthalmitis is feared, an extinguished ERG is a further justification for early enucleation.

Eyes with normal ERGs (Group IV) almost always achieved a good recovery of vision, even after very severe trauma. Eyes with subnormal ERGs (Group III) showed a recovery of vision almost as good as that in Group IV. This leads to a consideration of the influence on the ERG of traumatic opacities of the ocular media. Cataracts are known to have little effect (Jayle and others, I968, Tassy, I966; Tassy and others, 1968; Burian and Burns, 1966), but intraocular haemorrhages may cause more modification. To investigate this we tested normal subjects by inserting glass containers full of human blood between the flash and the subject. The subjects were tested successively with blood thicknesses ranging from 0.5 to $10 \mathrm{~mm}$. We used flashes of intensity 4 .

With white stimuli, and up to I $\mathrm{mm}$. thickness of blood, the amplitude of the ERG diminishes by only io per cent., but the responses get a scotopic pattern; with a $2 \mathrm{~mm}$. thickness of blood the amplitude diminishes to 30 per cent. of the normal; with $3 \mathrm{~mm}$. to 20 per cent., and $5 \mathrm{~mm}$. to zero.

With red stimuli the first millimetre of blood changes neither the amplitude nor the shape of the responses; $2 \mathrm{~mm}$. reduces the amplitude to $5^{\circ}$ per cent. of the normal, and with $5 \mathrm{~mm}$. the ERG disappears.

Responses to blue stimuli are much more sensitive; they are reduced to 25 per cent. of the normal by a $0.5 \mathrm{~mm}$. thickness of blood and with I mm. the ERG disappears.

The drastic changes obtained experimentally with a $2 \mathrm{~mm}$. thickness of blood (and with only $0.5 \mathrm{~mm}$. for the blue stimuli) seem to contradict our clinical results: normal and subnormal ERGs were obtained in many patients with extensive haemorrhages (e.g. Case 3); moreover all patients with extinguished or greatly diminished ERGs, in whom the fundus became visible later, had retinal damage explaining the reduction of the ERG. However several facts may explain the small effect of the blood filter on clinical findings:

(i) The blood in the eye is mixed with aqueous humour and vitreous, so that the thickness of the blood filter seems to be greater than in fact it is.

(ii) The anterior chamber is $3 \mathrm{~mm}$. deep only in its central part.

(iii) Some light passes through the conjunctiva, sclera, and pigment epithelium.

Several reasons led us to think that the amplitude of the responses to white stimuli would be the best criterion by which to classify the ERGs:

(i) Our experiments showed that the responses to blue stimuli were too sensitive to the filtration of light by blood to be a good criterion; the $b_{2} / b_{1}$ ratio of responses to white stimuli was similar.

(ii) With the stimuli used, the responses to white flashes have a greater amplitude than those to red or blue stimuli, and are therefore easier to measure accurately against background noise caused by the movements of the patient. However, we tried to classify the ERGs by other criteria such as amplitude of the responses to red or blue stimuli, $b_{1} / b_{2}$ ratio, $b / a$ ratio, or amplitude of the oscillatory potential, but none gave a prognosis as accurate as the prognosis given by the amplitude of the responses to white stimuli. Even 
so the ERG may be modified by opacities of the ocular media and the recording technique which must be used in these damaged eyes. Therefore, only gross abnormalities of thछ ERG must be taken into account. This probably explains why patients with subnormat ERGs (Group III) had a visual recovery similar to that of those with normal ERGs (Group IV). Moreover, with the stimuli generally used it would not be possible to diagnose localized macular lesion, but there was no such case in our series.

Some eyes showed a marked decrease in the amplitude of the responses when the ER was repeated a few days or weeks after the first. In two cases the fundus became visible later and a retinal detachment was seen. A normal ERG soon after the trauma does not preclude the occurrence of a late retinal detachment which can be diagnosed by a decreasè in the amplitude of repeat ERGs.

It has already been reported (Jayle and others, I965; Karpe, I945; Henkes, I957오. Straub, I96I; Gliem, I965) that, in contusions of the eye, the modification of the ERG i\& approximately proportional to the extent of the retinal damage, but the use of the ERG in serious and recent trauma was not discussed. However, in these eyes, in which oedemar and haemorrhage often obscure the fundus the ERG has greater clinical value. Oup special recording techniques allowed us to record the ERG during the first few days afterthe trauma, even in very severe cases.

\section{Summary}

The electroretinogram was recorded in $6 \mathrm{r}$ cases of recent and severe ocular trauma in which opacities of the ocular media prevented the ophthalmoscopic examination of the fundus. In perforating wounds the usual contact lens electrode was replaced by a hooke shaped eyelid retractor electrode or a skin electrode. This allowed the ERG to be recorded during the first few days after the trauma. All patients in whom the ERG was extremely small or no ERG could be elicited later failed to recover their sight, and contrari wise almost every patient with a normal or slightly subnormal ERG achieved a good recovery of vision, even after very serious trauma. The ERG recorded soon after severe ocular trauma has therefore an important prognostic value.

\section{References}

BURIAN, H. M., and BURNS, c. A. (I966) Docum. ophthal. (Den Haag), 20, I4I GLIEM, H. (1965) v. Graefes Arch. Ophthal., 168, 513

HENKES, H. E. (1957) Amer. J. Ophthal., 43, 67

JAYLE, G. E., BOYER, R. L., and CAMO, R. L. (1959) “L'électrorétinographie dynamique en ophtalo mologie". Masson, Paris

Soc. franç. Ophtal.). Masson, Paris

(1965) “L’électrorétinographie" (Rapport présenté à l⿳亠口冖̆

, TASSY, A. F., and GRAVELINE, J. (1968) In "The Clinical Value of Electroretinography"

Symposium at Ghent, August, i966, ed. J. François, pp. 425-34. Karger, Basel and New Yorlo JACOBSON, J. H., UCHIDA, S., and MASUDA, y. (1966) "Non-corneal Electrode for Clinical ERG", 4tî

Symposium of ISCERG, Hakone, 1965. Jap. 7. Ophthal., ro, Suppl., p. 204

KARPE, G. (1945) "The Basis of Clinical Electroretinography". Acta ophthal. (Kbh.), 24, Supplo STRAUB, W. (196r) "Das Elektroretinogramm: Experimentelle und klinische Beobachtungen"

Bücherei des Augenarztes, Heft 36 . Enke, Stuttgart

TASSY, A. F. (1966) "Use of Averaging in Ophthalmologic Electrophysiology and Electrodiagnosis

(in English and French)". Medical thesis, Marseilles

, JAYLE, G. E., and GRAVELINE, J. (1968) In "The Clinical Value of Electroretinography"

Symposium at Ghent, August, 1966, ed. J. François, pp. 32-45. Karger, Basel and New York 